https://doi.org/10.32735/S0718-2201202000050796

$311-322$

\title{
LA PRESENCIA Y FUNCIONES DEL AUTOR IMPLÍCITO REPRESENTADO EN LAS NOVELAS DE ROALD DAHL
}

The presence and functions of the implied author represented in the Roald Dahl novels

\author{
ÓSCAR JOSÉ MARTÍN SÁNCHEZ \\ Universidad Pontificia de Salamanca (España) \\ ojmartinsa@upsa.es
}

\section{INTRODUCCIÓN}

Gracias a Genette, que identificó la voz narrativa y la diferenció del modo, es posible estudiar aspectos vinculados a las peculiaridades de quien se expresa en la narración. El estudioso francés planteó la importancia de la observación y del análisis de los aspectos relacionados con el tiempo y con el sujeto de la enunciación que residen en el discurso narrativo, pues sus múltiples variaciones reflejan uno de los valores identificativos de los textos contemporáneos. El lector es guiado por una voz que transmite una información que, asumida y referida por la figura de un personaje o por una entidad independiente de la otra, pretende captar su atención y obtener con ella el pacto narrativo. Para que se dé esta situación, entre otros factores, debe articularse en función de las exigencias del lector posible. Estas, según Genette (1989, pp. 272-273) son las que reflejan las relaciones entre las diferentes instancias narrativas:

Una situación narrativa, como cualquier otra, es un conjunto completo en el que el análisis, o simplemente la descripción, no pueden distinguir sino desgarrando un tejido de relaciones estrechas entre el acto narrativo, sus protagonistas, sus determinaciones espaciotemporales, su relación con las demás situaciones narrativas implicadas en el mismo relato, etcétera.

Por otro lado, interesa en este trabajo detenerse en el parámetro de la voz narrativa pues tradicionalmente los textos literarios infantiles y juveniles han estado marcados por el principio de simplicidad. Dicha condición está tendiendo a transformarse en narrativa infantil y juvenil contemporánea sobre todo en lo que se refiere a la estructura y a la perspectiva según ha demostrado la investigadora catalana Teresa Colomer (1998, pp. 302303), quien explica que el viraje hacia estructuras más complejas podría deberse a la adaptación hacia los nuevos patrones literarios:

[...] la evolución literaria de la producción que ha introducido modelos literarios que requerían nuevas condiciones de enunciación. Sin embargo, este punto parece especialmente condicionado por el principio de comprensibilidad que rige este tipo de literatura. Por ello, las complicaciones producidas son bastante limitadas en cuanto a sus posibilidades y guardan una estrecha relación con los presupuestos respecto de la edad lectora a la que se dirigen. 
Uno de los motivos que explican la transformación del discurso narrativo infantil y juvenil actual tiene que ver, como explica Colomer, por el proceso de psicologización con el que se ha ampliado sustancialmente el ámbito temático que ha favorecido sin duda la presencia de puntos de vista narrativos cercanos al mundo íntimo del personaje con el que el lector inexperto puede sentirse identificado. Por lo que se podría pensar que la instancia narrativa también forma parte esencial en el proceso de acercamiento al lector a participar activamente en la acción narrativa e ir perdiendo su función clásica de actuar como guía y protector del lector. Se atestigua pues la tendencia a la variabilidad de voces narrativas que dotan de mayor viveza al discurso narrativo y apelan visiblemente al lector. A todo esto se añade la posibilidad de incorporación de otras herramientas de anclaje, como son los recursos paratextuales (ilustraciones, uso de diferentes tipografías, manipulación de formatos, etc.) que amplían las posibilidades expresivas del discurso escrito allanando el camino de comprensión del receptor.

Independientemente de la representación gramatical del sujeto enunciador, partimos de un $y o$, por lo que no se puede confundir la concreción en primera o tercera personas en la enunciación con la identificación de quien enuncia, siempre yo. Genette señala que la elección de la persona de la enunciación no se establece mediante las formas gramaticales, sino entre las diversas actitudes establecidas a la hora de abordar una historia:

1. La de participación en la historia: narrador homodiegético o autodiegético si además es protagonista.

2. La de no participación en la historia: narrador heterodiegético.

La diferencia esencial entre ambas posiciones podría explicarse mediante la variabilidad del calibre en cuanto a la objetividad; se podría pensar que el narrador que participa en la historia esconde la intención de mayor objetividad gracias a la recreación de la idea de verosimilitud que ocupa la perspectiva del relato autobiográfico. Sin embargo, esta misma intención se puede atestiguar desde la otra posición como testigo de los hechos enunciados. Esto confirma la relatividad en la elección de una u otra voces narrativas en cuanto a su alcance intencional y la posibilidad de mutabilidad en un mismo relato.

Con respecto a la situación de narrador en relación a lo narrado puede estar representada por el lector por medio de diferentes niveles de profundización considerando la relación establecida entre el narrador con los elementos que conforman la historia. Por ejemplo, la representación del espacio o del tiempo pueden ser determinantes a la hora de establecer una relación determinada del narrador con lo que cuenta. Así, se distinguen tres niveles narrativos según los tipos de relaciones diegéticas establecidas por Genette:

1. Relación extradiegética: el narrador no forma parte de la historia sino que se encarga de contarla, por lo tanto es una acción presente en todo el acto de la enunciación.

2. Relación intradiegética: idéntica a la anterior pero con una relación extradiegética con respecto a la narración primera. 
La presencia y funciones del autor implícito representado en las novelas de Roald Dahl.

3. Relación metadigética: igual que la anterior pero con una relación extradiegética con respecto a la narración segunda.

La combinación de relaciones se presenta como un juego de variabilidad que confiere vitalidad al relato, se aleja de la linealidad discursiva y amortigua el impacto de artificio ficcional. Un ejemplo de dicho juego aparece al inicio de la novela Charlie y la fábrica de chocolate de Dahl, cuando el autor representado (dimensión extradiegética) presenta al protagonista (dimensión diegética) y abandona inmediatamente su plano para ocupar el de narrador homodiegético para saludarlo; el protagonista le contesta. A continuación, el narrador vuelve a su plano de autor representado para informar a los lectores implícitos representados de que el personaje se alegra de conocerlos (en lo sucesivo, incorporamos entre corchetes el número de la página donde se encuentra el fragmento seleccionado de la obra a la que se refiere):

[12] El señor y la señora Bucket tienen un hijo, que se llama Charlie Buckett.

Este es Charlie. ¿Cómo estás? Y tú, ¿cómo estás?

Charlie se alegra de conoceros.

Las combinaciones de niveles narrativos posibles son abundantes y no en todo el relato deben aparecer necesariamente, aunque es importante resaltar que, cuando lo hacen, están por alguna razón narrativa. Genette distingue tres tipos de relaciones digéticas en el nivel metadigético, por ser este el más fuertemente engarzado en la estructura narrativa:

1. Función explicativa: la inserción de una nueva historia expresa, desarrolla, justifica o aclara algún fenómeno relatado anteriormente.

2. Función temática: la introducción de la información se explica por contraste o analogía con respecto al relato primero.

3. Función de distracción o de obstrucción: la aparición de este tipo de relación es pertinente gracias al propio acto de la narración, que implica la construcción de situaciones variadas.

La combinación que sucede al pasaje anterior, de autor implícito representado por un narrador homodigético, enlaza a continuación en el nivel metadiegético con la aparición de un narrador no participante de la acción narrativa que retoma el contenido sobre el que se estaba hablando, desarrollando temas de la casa y de los miembros de la familia de Charlie a los que se había referido:

[12] [...] viven juntos en una casita de madera en las afueras de la ciudad. La casa no eral lo bastante grande para tanta gente...

El autor implícito había mencionado tanto el número de personas que vivían en la casa como las pequeñas dimensiones de la misma. Inmediatamente después, el narrador extradiegético amplía el alcance de su función para dar más información sobre los temas, 
cumpliendo así la función explicativa de tal desarrollo: la casa era muy pequeña y por eso era incómoda para tanta gente.

Otro caso singular es el que encontramos en Matilda cuando el autor implícito representado explica y juzga la actitud de algunos padres que idolatran a sus hijos aun siendo estos un verdadero desastre, para después, gracias al cambio en la voz narrativa, explicar el caso opuesto que se recrea a lo largo de todo el relato. Así, este cambio desempeñará una función igualmente temática pero en este caso por contraste:

13] A veces se topa uno con padres que se comportan del modo opuesto. Padres que no muestran el menor interés por sus hijos y que, naturalmente, son mucho perores que los siente un cariño delirante. El señor y la señora Wormwood eran de esos.

La transgresión de planos narrativos, eludiendo incluso planos intermedios, es denominada metalepsis por Genette. Claro es el ejemplo en el que se insertan en medio del relato momentos en los que el narrador presenta explícitamente a un personaje o reconduce el hilo de la narración. El efecto que este recurso provoca sobre el lector es de comicidad o fantasía. Lo que podría explicar la frecuente aparición de esta estrategia en la narrativa de Dahl. Hay que reseñar, por otro lado, que el consentimiento del tránsito de un plano a otro en el fragmento anterior se ve favorecido por las imágenes que acompañan al texto, que reflejan a los miembros de la familia de Charlie. En esta secuencia, abandonan su plano intradiegético y complementan la información que transmite el narrador en su función de presentador, aunque es el lector implícito representado quien sirve de puente de unión entre el personaje y el lector:

[12] Charlie se alegra de conoceros.

\section{EL AUTOR IMPLÍCITO REPRESENTADO: ANCLAJE PARA LA COMPRENSIÓN DEL LECTOR}

Partimos del hecho de la existencia de una doble consideración del autor literario: por un lado, como ente factor del relato y, por otro, como elemento posible constituyente del discurso literario en oposición/complementación del narrador. Por tanto es necesario hacer una distinción entre el autor que vive, que realiza varias funciones en la vida real, y el que participa en el pacto narrativo, de manera que conviene considerar al autor dentro de la novela como una participante propio del enunciado ficcional, al igual que se identifica el destinatario como receptor posible y que asume las reglas impuestas por la ficción y no como lector real. Así, tomando como base la distinción categorial establecida por Yvancos (1992, p. 99) en la que se establecen cuatro dimensiones simétricas, se distinguen:

1. Autor real/lector real

2. Autor implícito no representado/lector implícito no representado

3. Autor implícito representado/lector implícito representado

4. Narrador/narratario 
Las dos primeras categorías quedan fuera de lo estrictamente narratológico pues pertenecen al ámbito de lo sociológico, mientras que las dos siguientes se incorporan a la dimensión interpretativa desde un punto de vista literario. Así, el autor implícito representado, a pesar de las dificultades que a menudo supone su diferenciación con respecto al narrador, presenta ciertos rasgos distintivos que se podrían considerar orgánicos, frente a los no orgánicos propios del narrador. Se ha optado por tal nomenclatura pues creemos que posee aquel, rasgos biológicos más cercanos al discurso oral improvisado que al discurso formal escrito, como se puede observar en el siguiente fragmento extraído de Matilda:

[10] Ocurre una cosa graciosa con las madres y los padres. Aunque su hijo sea el ser más repugnante que uno pueda imaginarse, creen que es maravilloso. Algunos padres van aún más lejos. Su adoración llega a cegarlos y están convencidos de que su vástago tiene cualidades de genio. Bueno, no hay nada malo de ello. La gente es así. Sólo cuando los padres empiezan a hablarnos de las maravillas de su descendencia es cuando gritamos: “¡Tráigame una palangana! ¡Voy a vomitar!”.

La aparición de la voz del autor es frecuente en las cuatro novelas traídas al análisis en este artículo. La singularidad de la aparición de la voz del autor hasta el momento mismo del comienzo de la acción narrativa podría ser considerada el punto de partida del proceso de ficcionalización posterior. No obstante, no hay que olvidar que los títulos de los capítulos a menudo contienen información que pertenece a la diégesis del relato y desempeñan así una función proléptica de adelantar el contenido o paraliteraria. Como consecuencia, se crea desde el inicio un juego basado en la alteración de planos narrativos en los que se constata la variabilidad de sujetos de la enunciación entre el yo-yo y el yo-él: en Charlie y..., por ejemplo, en el primer capítulo, el sujeto de la enunciación coincide en la forma yo-yo en parte del desarrollo del capítulo ([16] "Pero aún no os he hablado de la única cosa que torturaba al pequeño Charlie...”), aunque su título responde al esquema yo-él ([11] “Aquí viene Charlie"). Tal juego se hace manifiesto no sólo en el caso de los títulos y el propio relato sino también en el relato mismo.

Las intervenciones del autor en Matilda y en Los Cretinos son singularmente representativas, pues se extienden en el cuerpo del relato con frecuencia, y llegan a ser, en la segunda de las novelas, la voz principal del primer capítulo, como se demuestra en el final del mismo:

[10] No lo sé. Pero la próxima vez que veas a un hombre con barba (lo cual sucederá tan pronto como salgas a la calle) seguramente lo mirarás más de cerca y empezarás a preguntarte por estas cosas.

Desde un punto de vista formal, esta voz aparece asociada al presente de indicativo con carácter pancrónico ("ocurre", "hay", "se deja", "empiezan") frente al imperfecto 
empleado como tiempo identificativo de la diégesis del relato ("era", "esperaban", "resplandecía", etc.) [Formas verbales extraídas alternativamente de Matilda y Los Cretinos.]. Por otro lado, el uso del presente de indicativo favorece la sincronía de planos entre el autor implícito representado y el receptor implícito representado o narratario. Se genera en dicha conexión una estabilidad entre "personas actuales de la enunciación" (yo y tú) y “tiempo actual" (presente) que contrasta con la estabilidad entre persona (yo y él) y tiempos (del pasado) de la diégesis posterior, como se observa en Los Cretinos:

[12] Cuando los muy peludos se lavan la cara, debe de ser para ellos un trabajo tan grande como cuando tú y yo nos lavamos la cabeza.

Frente a: [9] "El señor Cretino era uno de estos hombres barbudos".

Es importante destacar que en estas cuatro novelas la voz del autor se hace sustancialmente más presente en el transcurso de los primeros capítulos que en el resto del relato. En Matilda es el autor el que da comienzo al discurso haciendo una reflexión en la que evalúa duramente la consideración equivocada de ciertos padres hacia sus hijos, y extiende dicha reflexión hasta que da comienzo al relato propiamente dicho. El autor establece una suerte de contrastes entre aquellos padres que enaltecen ciegamente a sus hijos y los que se comportan de modo radicalmente opuesto, tipología que se va a reflejar detalladamente a lo largo de la narración:

[11] Aunque su hijo sea el ser más repugnante que uno pueda imaginarse, creen que es maravilloso.

[13] Padres que no demuestran el menor interés por sus hijos y que, naturalmente, son mucho peores que los que sienten un cariño delirante.

Formalmente, son frecuentes las estructuras oracionales enunciativas empleadas para materializar esta voz, gracias a las cuales se pone de manifiesto una posición clara y contundente, quizá radical por el uso de determinados calificativos, ante lo que cuenta:

[11] Sólo cuando los padres empiezan a hablarnos de las maravillas de su descendencia es cuando gritamos: “ ¡Tráiganme una palangana! ¡Voy a vomitar!”. Los maestros lo pasan muy mal teniendo que escuchar estas tonterías de padres orgullosos, pero normalmente se desquitan cuando llega la hora de las notas finales del curso.

Tal contundencia en los enunciados extraídos de Matilda se ve reforzada por el empleo de calificativos opuestos en breves párrafos ("repugnante","maravilloso", "genio", "auténtico desastre"), estructuras superlativas y sintagmas adjetivales con modificadores y cuantificadores ("el ser más repugnante", "aún más lejos", "muy mal", "auténtico desastre", "especialmente odiosa"), y expresiones hechas y comparaciones que 
La presencia y funciones del autor implícito representado en las novelas de Roald Dahl.

evidencian la opinión crítica y mordaz del autor al respecto (“... es seguro, como hay infierno"; "... su hijo Wilfred ha pasado seis años como larva en esta escuela y aún estamos esperando que salga de la crisálida").

En Los Cretinos y La maravillosa... sucede algo parecido: la voz del autor se muestra radical, emplea similares recursos expresivos y evidencia su posición claramente antes de dar paso a la voz del narrador:

[Los Cretinos, 9] Cuando un hombre se deja crecer el pelo por toda la cara es imposible adivinar qué aspecto tiene.

[La maravillosa..., 9] Es una tontería decirle a un niño semejante cosa en cualquier ocasión.

Sin embargo, en Charlie y... la voz del autor desempeña una función de presentación con la que se minimiza, aunque no desaparece por completo la valoración personal en la que prevalece la claridad enunciativa alejada de toda subjetividad:

[11] Estos dos señores tan viejos son el padre y la madre del señor Bucket. Se llaman abuelo Joe y abuela Josephine. Y estos dos señores tan viejos son el padre y la madre de la señora Bucket. Se llaman abuelo George y abuela Georgina.

Así, la voz del autor desempeña en estas novelas una función digresiva, en la que muestra abiertamente su forma de discurrir, que sirve para contextualizar la situación que seguidamente se va a relatar, y toma una posición que justifica la elección de los acontecimientos elegidos por el narrador de la diégesis. El autor comparte ideología con este, se encuentra en sincronía interpretativa con él.

Por otro lado, se halla diseminada a lo largo de estas novelas la manifestación de la voz del autor desempeñando diversas funciones que se podrían ordenar de la siguiente forma:

1. Función digresiva: la voz del autor expresa una opinión personal acerca del contenido que está narrando aunque, a veces, recurre a las generalidades del saber común.

2. Función explicativa o temática: la voz del autor desarrolla algún contenido que cree conveniente definir para justificar la pertinencia de la información que narra o porque considera que el narratario carece de la formación suficiente para comprenderlo o simplemente para enfatizarlo.

3. Función estructuradora: la voz del autor retoma, adelanta, redirige u ordena la narración con el fin de dotar de cohesión al discurso narrativo.

4. Función de desviación paratextual: la voz del autor invita al lector a salirse del texto para atender a otros elementos que no son estrictamente textuales, como las ilustraciones, o a adoptar determinada línea de pensamiento o acción para enfrentarse al contenido del texto. 
2. ANÁLISIS FUNCIONAL DEL AUTOR IMPLÍCITO REPRESENTADO EN CUATRO NOVELAS DEROALD DAHL

A continuación, mediante la recogida de fragmentos de las novelas seleccionadas, se evidencia la variabilidad de la voz narrativa que refleja al autor implícito representado y cuáles son las funciones más frecuentes según los descriptores anteriormente expuestos con el objetivo de extraer conclusiones determinantes para conocer su comportamiento:

\subsection{FUNCIÓN DIGRESIVA}

\section{Matilda}

[9-13] "Ocurre una cosa graciosa con las madres [...] informes de fin de curso de las sabandijas de mi clase"

[40] "Hay muchas cosas que vuelven irritables a un hombre cuando vuelve a casa del trabajo, y una mujer lista padecía por lo general los síntomas de tormenta y lo deja solo hasta que se calma".

[68] "Gracias a Dios, no nos topamos con muchas personas asíen el mundo, aunque las hay y todos nos encontramos, por lo menos, con una de ellas en la vida".

[82] "A la mayoría de los directores de escuela los eligen porque reúnen ciertas cualidades. Comprenden a los niños y se preocupan de lo que es mejor para ellos. Son simpáticos, amables y les interesa profundamente la educación".

\section{Los Cretinos}

[64] "Esto suena a majadería para ti y para mí".

La maravillosa medicina de Jorge

No hay.

Charlie y la fábrica de chocolate

[56] "No sé qué ocurre en los días fríos que da un enorme apetito. La mayoría de nosotros nos sorprendemos deseando espesos guisos y tibios trozos de pastel de manzana y toda clase de deliciosos platos calientes, y teniendo en cuenta que somos mucho más afortunados de lo que pensamos, a menudo obtenemos lo que deseamos, o casi".

\subsection{FUNCIÓN EXPLICATIVA O TEMÁTICA}

\section{Matilda}

[13] "Una postilla es algo que se tiene que soportar hasta que llega el momento de arrancársela de un papirotazo y lanzarla lejos". 
[34] "La supercola es un producto muy fuerte, tan fuerte que si se tira demasiado puede arrancarle a uno la piel".

[134] "La salamandra acuática es un animal horrendo, increíblemente feo, parecido a una cría de cocodrilo, sólo que con la cabeza más corta. Aunque no lo parece, es inofensivo. Mide unos quince centímetros de largo y es viscosa, con la piel de color gris verdoso por arriba y anaranjado en el vientre. Es, en realidad, un animal anfibio, que puede vivir tanto dentro como fuera del agua".

Los Cretinos

[13] "Como tú sabes, una cara normal, sin barba, como la tuya o la mía, simplemente se pone un poco churretosa si no se lava bastante a menudo, y no hay nada horrible en eso".

[15] "Lo que estoy intentando explicarte es que el señor Cretino era un viejo asqueroso y maloliente".

[18] "Si una persona tiene malas ideas, empieza a notarse en su cara. Y cuando esta persona tiene malas ideas cada día de la semana, cada año, su cara se va poniendo cada vez más fea hasta que es tan horrible que apenas puedes soportar mirarla".

[18] "Una persona que tiene buenos pensamientos nunca puede ser fea. Puedes tener una nariz deforme, la boca torcida, una doble barbilla y los dientes salidos, pero si tienes buenos pensamientos, resplandecerán en tu cara como rayos de sol y siempre tendrás algún atractivo".

[21] "Se pueden hacer un montón de trucos con un ojo de cristal porque puedes sacártelo y volvértelo a poner todas las veces que quieras. Puedes apostar tu vida a que la señora Cretino se conocía todos estos trucos".

[25] "Las brujas viejas y sucias como ella siempre tienen picores en la tripa".

[27] "Cuando la señora Cretino volvió en sí, la rana acababa de saltar encima de su cara. Esto no es una cosa agradable para que le pase a uno de noche en la cama". [34] "Ahora bien, cuando algo crece muy lentamente es casi imposible notarlo. Tú mismo, por ejemplo, en realidad, estás creciendo cada día que pasa, pero no te das cuenta".

[59] "Esto no tiene nada de malo".

La maravillosa medicina de Jorge

[10] "La mayoría de las abuelas son señoras encantadoras amables y serviciales, pero ésta no".

[61] "Las gallinas son unas aves muy tontas y muy voraces. Creen que todo es comida. Ésta pensó que la cuchara estaba llena de grano. Se acercó a saltitos, torció la cabeza a un lado y miró la cuchara".

Charlie y la fábrica de chocolate

[14] "Pero un taponador de tubos de pasta dentífrica nunca gana mucho dinero [...]". 


\subsection{FUNCIÓN ESTRUCTURADORA}

\section{Matilda}

[13] "Pero ya está bien de esto. Tenemos que seguir".

[31] "Recuerden que aún no tenía cinco años y que, a esa edad, no es fácil marcarle un tanto a un todopoderoso adulto".

[58] "Como ya sabemos, la señora Wormwood llevaba el pelo teñido de un color rubio platino resplandeciente, muy parecido al reluciente color plateado de las mallas de una equilibrista de circo».

[68-69] "Si le pasa a usted, compórtese igual que si se hallara ante un rinoceronte furioso en la selva; súbase al árbol más cercano y quédese allí hasta que se haya ido. Es casi imposible describir a esta mujer, son sus excentricidades y su aspecto, pero intentaré hacerlo un poco más adelante. Dejémosla de momento y volvamos a Matilda y su primer día en la clase de la señorita Honey".

Los Cretinos

[51] "Pero ya es suficiente. No podemos continuar siempre observando a estos dos desagradables personajes haciéndose cosas desagradables el uno al otro. Debemos proseguir con la historia".

[53] 'Dentro hay cuatro monos. Pertenecen al señor Cretino. Oirás hablar de ellos más adelante".

[63] "Ahora vamos con los monos".

La maravillosa medicina de Jorge

No hay.

Charlie y la fábrica de chocolate

No hay.

\subsection{FUNCIÓN DE DESVIACIÓN PARATEXTUAL}

\begin{tabular}{|l|}
\hline Matilda \\
\hline No hay. \\
\hline Los Cretinos \\
\hline [14] "Tápense bien las narices, señoras y caballeros". \\
[18] "Échale un vistazo". \\
[51] "Aquí hay un dibujo de la casa y del jardín del señor y la señora Cretino. \\
¡Menuda casa! Parece una cárcel. Y no hay ventanas por ningún sitio". \\
[52] "Cerca de la casa puedes ver el taller del señor Cretino. A un lado se encuentra \\
el Gran Árbol Muerto. Nunca tiene hojas porque está muerto". \\
\hline
\end{tabular}




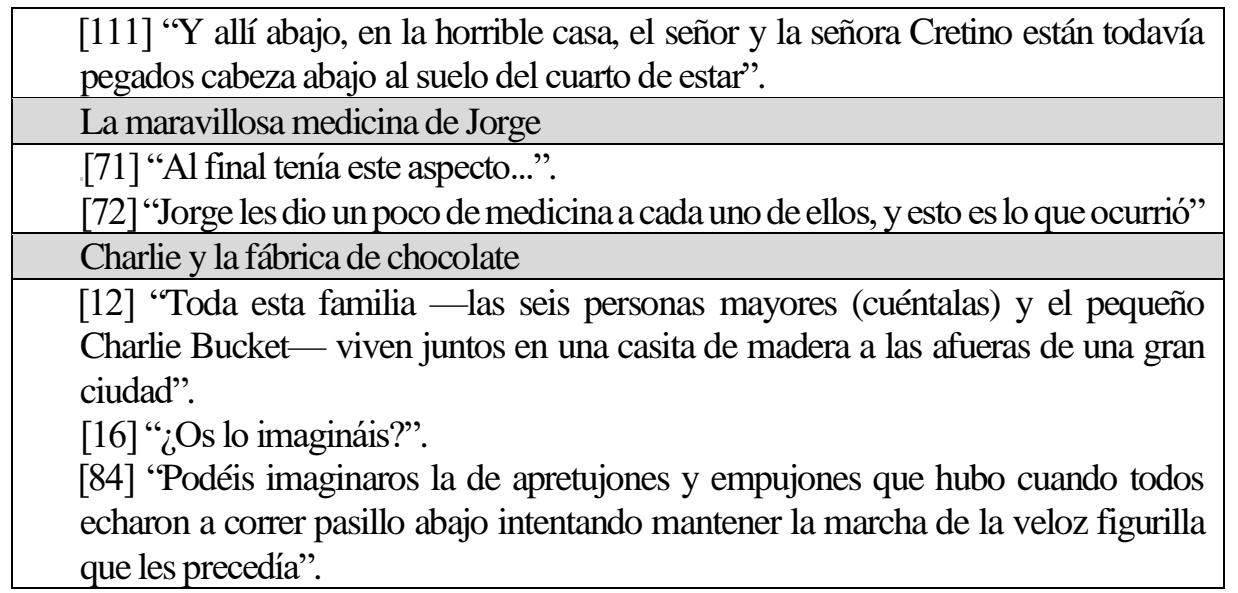

\section{CONCLUSIONES}

Tras la selección y clasificación de fragmentos en los que aparece la figura del autor implícito representado, observamos su presencia y su frecuente variabilidad en las cuatro novelas elegidas en este trabajo, con lo que se puede suponer que es un plano que identifica y forma parte de la naturaleza narrativa de Dahl. Además, teniendo en cuenta el número de ejemplos posibles extraídos de las novelas escogidas, podríamos afirmar que la función más habitual es la explicativa o temática, ya que es la única que aparece en todas las novelas y con una diferencia en cantidad suficientemente significativa. Por otro lado, la menos frecuente es la estructuradora, con una ausencia total en dos de las novelas analizadas. La función digresiva, con una presencia bastante acusada en todas las novelas, desvela la identidad y el temperamento del autor dotando al contenido de la historia una clara intención cómica. La función paratextual, atestiguada en las novelas en la misma proporción que la anterior, consiente tanto la incorporación de recursos gráficos (ilustraciones) muy habituales en literatura infantil y juvenil con el objetivo de completar y ampliar el sentido del texto.

Con toda probabilidad, la razón que justifique la aparición de las variables funcionales con predominancia de la explicativa o temática de autor implícito representado se deba al principio de adaptabilidad al lector posible de aquel que, como entidad ficcional más cercana a lo orgánico, se acomoda a la inexperiencia vital y literaria del joven lector estableciendo con él una sincronía comunicativa con cierto matiz didáctico, del que Dahl era consciente. 
Óscar José Martín Sánchez

OBRAS CITADAS

Colomer, T. (1998). La formación del lector literario, Fundación Germán Sánchez Ruipérez, Madrid.

Dahl, R. (2010a). La maravillosa medicina de Jorge, Alfaguara Juvenil, Madrid [1. a ed.: 1981, George's Marvellous Medicine, Puffin Books, Londres].

— (2010b). Los Cretinos, Alfaguara Juvenil, Madrid [1. ${ }^{a}$ ed.: 1980, The Twits, Jonathan Cape, Londres].

— (2007). Charlie y la fábrica de chocolate, Alfaguara Juvenil, Madrid [1. ${ }^{a}$ ed.: 1964, Charlie and the Chocolate Factory, Alfred A. Knopf, Inc., Londres].

— (2001). Matilda, Alfaguara Juvenil, Madrid [1. a ed.: 1988, Matilda, Jonathan Cape, Londres].

Genette, G. (1989). Figuras III [trad. Carlos Manzano de Frutos], Lumen, Barcelona. [1. ${ }^{a}$ ed.: Figures III, Éditions du Seuil, París].

Pozuelo Yvancos, J. M. ${ }^{\text {a }}$ (1992). Teoría del lenguaje literario, Cátedra, Madrid. 